\title{
Preparation and Characterization of Antiepileptic Drugs Encapsulated in Sol-Gel Titania Nanoparticles as Controlled Release System
}

\author{
López $\mathrm{T}^{1,2,3^{*}}$, Cuevas $\mathrm{JL}^{1,2}$, Jardón $\mathbf{G}^{1}$, Gómez $\mathrm{E}^{3}$, Ramírez $\mathbf{P}^{1}$, Novaro $\mathbf{O}^{3,4}$ and Zavala-Tecuapetla $\mathrm{C}^{5}$ \\ ${ }^{1}$ Nanomedicine and Nanotechnology Laboratory, Universidad Autónoma Metropolitana-Xochimilco, México DF, México \\ ${ }^{2}$ Nanomedicine and Nanotechnology Laboratory, Hospital General Dr. Gea González, México DF, México \\ ${ }^{3}$ Physics Institute, Theoretical Physics Department, Universidad Nacional Autónoma de México, México DF, México \\ ${ }^{4}$ El Colegio Nacional, México DF, México \\ ${ }^{5}$ Instituto Nacional de Neurología y Neurocirugía MVS, México DF, México
}

\begin{abstract}
In this work Functionalized-titania nanoparticles containing different antiepileptic drugs (AEDs) (valproic acid, tiagabine, phenytoin, carbamazepine, lamotrigine) were developed and characterized. AEDs were encapsulated by adding them during the gelation step, in order to obtain a homogeneous phase. The nanoparticles obtained (empty and containing the drug) were characterized by N2 adsorption-desorption, FTIR spectroscopy, scanning electron microscopy, transmission electron microscopy and thermal gravimetric analysis. In addition, the delivery kinetics of the nanomaterials to study the drug release over the time was analyzed. It was demonstrated that the AEDs tested, may be encapsulated in functionalized-titania nanoparticles. Infrared spectra show that, because of the encapsulation process, the structure of the drug is not chemically altered. The SEM micrographs of nanoparticles containing the drugs show a heterogeneous microstructure formed by irregular aggregates, which are spherical in shape. The kinetic study to in vitro release to resultant nanomaterials was evaluated showing two different velocities: first a rapid release and then a slow and constant release.
\end{abstract}

Keywords: Epilepsy; Antiepileptic drug; Sol-Gel; Functionalizedtitania; Nanomaterials

\section{Introduction}

Epilepsy is a serious neurological condition characterized by recurrent seizures. It is highly refractory to pharmacological treatment, with over one third of patients continuing to experience seizures despite taking multiple antiepileptic drugs (AEDs) [1]. Most of AEDs face difficulties in achieving penetration through the blood-brain barrier $(\mathrm{BBB})$ and to reach to their target in the brain $[1,2]$. Another problem with the treatment is the systemic side effects due to the presence of the drug in the blood circulation, often in much higher levels than in the brain. Due to this, alternative therapies are urgently required. One drug-delivery solution with demonstrated potential is an intracranial implantable device that is capable of releasing AEDs to the seizure focus directly over long time periods, for instance in rat brains [3-6]. However, this approach would be clinically inappropriate. Implantation of the devices into patients with epilepsy would require invasive neurosurgical procedures that in themselves are not without risk. Intranasal delivery is emerging as a noninvasive option for delivering drugs to the central nervous system (CNS) with minimal peripheral exposure, avoiding side effects related to the AEDs. Additionally, this method facilitates the delivery of large (or charged) drugs, which fail to effectively cross the BBB [7]. The high degree of vascularization and high permeability of nasal mucosa makes the nose a portal for drug delivery. Nanoparticles may offer an improvement to nose-to-brain drug delivery, since they are able to protect the encapsulated drug, from biological and/or chemical degradation, they cross the BBB that would increase availability of the drug in the brain but also release the drug in a controlled way [8].

Several means of delivery have been studied (nanoparticles, nanocapsules, nanotubes, micelles, microemulsions, liposomes) that represent a therapeutic alternative [9-14]. Titania reservoirs synthesized by the sol-gel method for delivery of neurological drugs to the brain, have previously proved to be efficient for drug administration. Have been demonstrated that they are biocompatible, nontoxic and bioactive when implanted in the body $[3,4,15]$. Administration of AEDs encapsulated within titania nanoparticles could have advantages like the ability to increase the solubility of poorly water soluble drugs (eg. carbamazepine, phenytoin, lamotrigine), improving its chemical stability and reducing drug-related side effects.

In this study, we investigated these kinds of nanoparticles incorporating different antiepileptic drugs within the functionalized matrix, with the goal to generate nanomaterials with suitable properties that will allow their intranasal administration. The porosity of these nanoparticles was measured by nitrogen adsorption using the BET equation. We characterized their structural properties made by Fourier transform infrared spectroscopy (FTIR), thermal gravimetric analysis (TGA) and the morphology composition by scanning electron microscopy (SEM). Finally, we analyzed the delivery kinetics of the nanoparticles to study the drug release over the course of time.

\section{Experimental Methods}

\section{Procedure}

From SIGMA (Sigma-Aldrich, St Louis, MO): titanium n-butoxide (97\%), 5,5-Diphenylhydantoin sodium salt (phenytoin, PHE), carbamazepine (CBZ), lamotrigine (LMT), valproic acid sodium salt (VPA), tiagabine hydrochloride (TGB), gamma-aminobutyric acid, ammonium hydrogen-phosphate. Ammonium sulfate (J. T. Baker), ethanol (Golden Bell, 99.5\%). The amounts used were calculated to obtain the molar ratios of AED:TiO $10: 1$.

*Corresponding author: Tessy Lopez, Nanomedicine and Nanotechnology Laboratory, Universidad Autónoma Metropolitana-Xochimilco, México DF, México Tel: 56063822 extn. 5034; E-mail: tessy3@prodigy.net.mx

Received July 28, 2015; Accepted November 12, 2015; Published November 17,2015

Citation: López T, Cuevas JL, Jardón G, Gómez E, Ramírez P, et al. (2015) Preparation and Characterization of Antiepileptic Drugs Encapsulated in Sol-Gel Titania Nanoparticles as Controlled Release System. Med chem S2:003. doi: 10.4172/2161-0444.1000003

Copyright: $\odot 2015$ López T, et al. This is an open-access article distributed under the terms of the Creative Commons Attribution License, which permits unrestricted use, distribution, and reproduction in any medium, provided the original author and source are credited. 
A mixture of titanium n-butoxide and ethanol was added dropwise over four hours period to deionized water, under constant stirring. After that, the mixture was functionalized with gamma-aminobutyric acid, phosphates and sulfates. Next, the resulting homogeneous sol was maintained under constant stirring at $60^{\circ} \mathrm{C}$, until the formation of the gel. Finally, the gels were dried at $36^{\circ} \mathrm{C}$ for a week.

The AEDs was dissolved and stirred in deionized water. After that, a mixture of titanium n-butoxide plus ethanol was added drop by drop during four hours under constant stirring. In addition, the mixture was functionalized and the resulting homogeneous sol was stirred at $60^{\circ} \mathrm{C}$ until the formation of the gel that was dried at $36^{\circ} \mathrm{C}$ for a week.

\section{Characterization}

$\mathrm{N}_{2}$ adsorption-desorption: $\mathrm{N}_{2}$ adsorption-desorption isotherms were recorded by using Belsorp II-BEL equipment (BEL Japan Inc., Osaka, Japan). The samples were vacuum treated at $40{ }^{\circ} \mathrm{C}$ for $48 \mathrm{~h}$ prior to the $\mathrm{N}_{2}$ adsorption-desorption measurement. Surface areas were obtained using the BET (Brunauer-Emmett-Teller) equation. Pore sizes and pore volumes were obtained by applying the BJH (BarretJoyner-Halenda) method.

Fourier transform infrared spectroscopy (FTIR): Infrared spectra were obtained using an IR-Affinity-1 Shimadzu spectrophotometer (Shimadzu Corporation, Tokyo, Japan) in the medium infrared region spectrum $\left(4000-400 \mathrm{~cm}^{-1}\right)$. The powders (with antiepileptic drugs and reference) were mixed with potassium bromide as a solid diluent to obtain a translucent wafer for analysis.

Scanning Electron Microscopy (SEM): For the SEM studies, a JEOL 5600 LV (Carl Ziess, Oberkochen, Germany) was used to investigate porous morphology and nanostructure of the samples as well as the chemical composition of each sample.

Transmission electron microscopy (TEM): TEM micrographs were taken using a JEOL JEM 2010F Field Emission Electron Microscope a morphology study and particle size measurements. Bright and dark field techniques were used in an effort to distinguish the particles from noise and particle clusters. For Bright field images the particles were identified by the orientation of atomic planes in the micrograph.

Thermal gravimetric analysis (TGA): Weight loss in each sample was determined by thermogravimetry using STA-i 1000 equipment (Instrument Specialists Inc., Wisconsin, USA). The samples were heated from room temperature up to $800^{\circ} \mathrm{C}$ using a heating rate of $10^{\circ} \mathrm{C} / \mathrm{min}$, under a nitrogen atmosphere.

In vitro release test: In vitro controlled release studies and kinetic analysis were performed under ambient conditions. AED-fTiO powder was compressed to form a tablet of approximately $50 \mathrm{mg}$ that was immersed in $50 \mathrm{~mL}$ of artificial cerebrospinal fluid (ACSF). AEDs release was monitored by ultraviolet spectroscopy through the increment of absorbance intensity (PHE, $220 \mathrm{~nm}$; CBZ, $280 \mathrm{~nm}$; LMT, 310; TGB, $250 \mathrm{~nm}$ ). A standard curve of known AEDs concentrations versus absorbance was used to determine the amount of AED released. UV spectra were taken at predetermined times in an S-3100 SCINCO spectrometer. The release experiments were performed in triplicate.

\section{Results}

Most oxides are gaining importance in the field of drug release due to their high porosity and large specific surface area, the place where the drug can be stabilized and released afterwards. The sol-gel process allows the manipulation of the synthesis parameters generating pores of several sizes. The textural properties were determined from nitrogen adsorption-desorption isotherms. Figure 1 shows the $\mathrm{N}_{2}$ adsorptiondesorption isotherms of functionalized-titania reference $\left(\mathrm{fTiO}_{2}\right)$ and their corresponding AED-containing forms $\left(\mathrm{AED}-\mathrm{fTiO}_{2}\right)$. They are shown as the gas absorbed by the unit mass plotted against the relative pressure. According to the IUPAC classification, the $\mathrm{fTiO}_{2}$ and AED$\mathrm{fTiO}_{2}$ isotherms can be classified as type IV, which is characteristic of mesoporous materials. The isotherms, at low relative pressures, show a concave knee which is characteristic of the monolayer formation followed by multilayer formation at higher relative pressures.

All isotherms are similar in shape, they do not present hysteresis loop so desorption process follows the same path that the adsorption process. However, the isotherms from CBZ- $\mathrm{fTiO}_{2}, \mathrm{LMT}-\mathrm{fTiO}_{2}$ and VPA-fTiO ${ }_{2}$ show a bigger volume of adsorbed nitrogen, resulting in an increase in the values of surface area and pore volume (Table 1).

TGB-fTiO 2 sample changed slightly respect to the $\mathrm{fTiO}_{2}$ in surface area and pore volume. For $\mathrm{PHE}_{\mathrm{fTiO}}$ sample, the surface area decreases slightly to $365 \mathrm{~m}^{2} / \mathrm{g}$ and its pore volume not change. For all samples ( $\mathrm{fTiO}_{2}$ and $\mathrm{AEDs}-\mathrm{fTiO}_{2}$ ) the pore diameter value was similar $(2.42 \mathrm{~nm})$ where according to the IUPAC pore size classification, this value is in the range of mesopores.

The chemical stability of encapsulated AED in the host material like $\mathrm{TiO}_{2}$ has been estimated by FTIR spectroscopy studies as reported in previous works $[5,16,17]$. AEDs structures are shown in Figure 2A. They contain in general the following functional groups: methyl, carboxyl, carbonyl, amine, hydroxyl, chloride and a benzyl ring group, which are detectable by infrared spectroscopy. For $\mathrm{fTiO}_{2}$ reference (Figure $2 \mathrm{~B}$ ), a wide band between 3500 and $2500 \mathrm{~cm}^{-1}$ was observed. It is formed by several signals derived from different modes of vibration of functional organic groups of $\mathrm{TiO}_{2}$. The signal centered at $3391 \mathrm{~cm}^{-1}$ was attributed to the stretching $\mathrm{O}-\mathrm{H}$ vibrations from adsorption of water on $\mathrm{TiO}_{2}$. A signal at $3208 \mathrm{~cm}^{-1}$ corresponds to the stretching $\mathrm{N}-\mathrm{H}$ vibrations from GABA while the bands at 2960, 2931, $2873 \mathrm{~cm}^{-1}$ correspond to asymmetric modes of vibration of $\mathrm{C}-\mathrm{H}$ bonds from alkyl groups linked to titania. The band at $1634 \mathrm{~cm}^{-1}$ corresponds to the adsorption of water on the surface of $\mathrm{TiO}_{2}$ due to symmetric stretching vibrations of hydrogen atoms linked to an oxygen atom in the water molecule; the bending vibrations of C-H groups appear at $1445 \mathrm{~cm}^{-1}$; the broad band observed after $1200 \mathrm{~cm}^{-1}$ is generated by Ti-O vibrations from titania structure. The signals from sulfate and phosphate groups linked to the

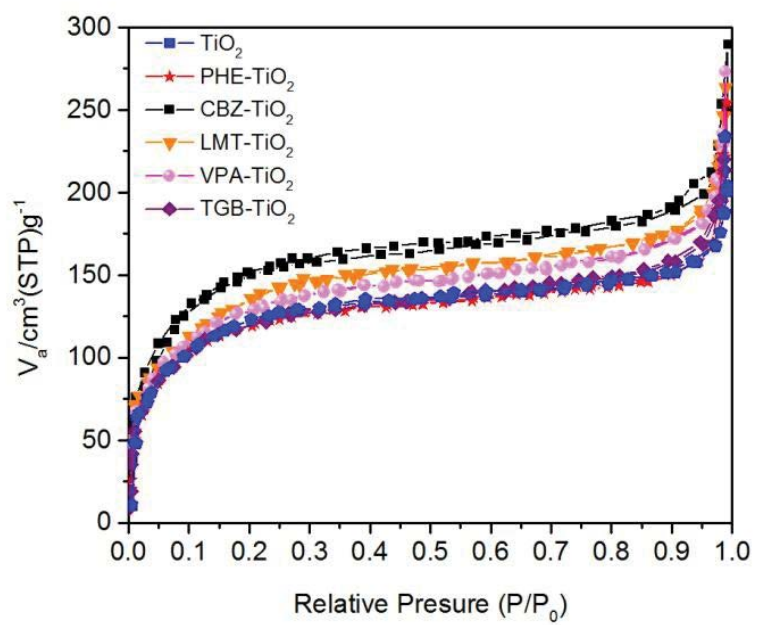

Figure 1: $\mathrm{N}_{2}$ adsorption-desorption isotherms of functionalized-titania reference ( $\mathrm{fTiO}_{2}$ ) and loaded with different AEDs (phenytoin PHE, carbamazepine CBZ, lamotrigine LMT, valproic acid VPA, tiagabine TGB). 


\begin{tabular}{|c|c|c|c|}
\hline Samples & $\mathrm{S}_{\text {Bet }}\left(\mathrm{m}^{2} / \mathrm{g}\right)$ & $D_{p}(n m)$ & $V_{p}\left(\mathrm{~cm}^{3} / \mathrm{g}\right)$ \\
\hline $\mathrm{TiO}_{2}$ & 439 & 2.42 & 0.16 \\
\hline PHE- $\mathrm{TiO}_{2}$ & 365 & 2.42 & 0.13 \\
\hline $\mathrm{CBZ}-\mathrm{TiO}_{2}$ & 547 & 2.42 & 0.25 \\
\hline LMT- $\mathrm{TiO}_{2}$ & 486 & 2.42 & 0.26 \\
\hline VPA-TiO & 485 & 2.42 & 0.29 \\
\hline TGB- $\mathrm{TiO}_{2}$ & 445 & 2.42 & 0.22 \\
\hline Samples & $\mathrm{S}_{\text {Bet }}\left(\mathrm{m}^{2} / \mathrm{g}\right)$ & $D_{p}(n m)$ & $V_{p}\left(\mathrm{~cm}^{3} / \mathrm{g}\right)$ \\
\hline $\mathrm{TiO}_{2}$ & 439 & 2.42 & 0.16 \\
\hline PHE- $\mathrm{TiO}_{2}$ & 365 & 2.42 & 0.13 \\
\hline $\mathrm{CBZ}-\mathrm{TiO}_{2}$ & 547 & 2.42 & 0.25 \\
\hline LMT- $\mathrm{TiO}_{2}$ & 486 & 2.42 & 0.26 \\
\hline VPA- $\mathrm{TiO}_{2}$ & 485 & 2.42 & 0.29 \\
\hline TGB- $\mathrm{TiO}_{2}$ & 445 & 2.42 & 0.22 \\
\hline
\end{tabular}

Table 1: Textural properties of $\mathrm{fTIO} 2$ reference and AEDs-fTiO2 samples. SBET is the surface area, $\mathrm{Dp}$ is the pore diameter, $\mathrm{Vp}$ is the pore volume.

surface of the $\mathrm{TiO}_{2}$ are observed at $900-700 \mathrm{~cm}^{-1}$ but they are masked by the signal from titania reference and cannot be identified. All these data confirm the functionalization of the $\mathrm{TiO}_{2}$ reference.

The AED-fTiO 2 spectrums consist of a wide band with small signals and others superimposed. The pattern of these spectrums is similar to $\mathrm{fTiO}_{2}$ reference as is indicated by the dotted lines. Signals from pure AEDs were masked by the intense signals of $\mathrm{fTiO}_{2}$ reference.

Figure $2 \mathrm{C}$ shows the FTIR spectra of pure VPA and VPA-fTiO in the region of $4000-1000 \mathrm{~cm}^{-1}$. The first spectrum corresponds to VPA. The band observed at $3441 \mathrm{~cm}^{-1}$ is assigned to the acid group $=\mathrm{COOH}$ and $\mathrm{OH}$ groups generated by water respectively. The bands observed at 2961 and $2931 \mathrm{~cm}^{-1}$ are due to $\mathrm{C}-\mathrm{H}$ symmetric and anti-symmetric stretching vibrations followed by the characteristic modes of $\mathrm{C}=\mathrm{O}$ at $2865 \mathrm{~cm}^{-1}$. At 1566 and 1558 , a strong band is observed due to the $\mathrm{CH}_{2}-$ $\mathrm{CH}_{3}$ asymmetric bending within the twist plane. The bands at 1453 and $1414 \mathrm{~cm}^{-1}$ correspond to stretching vibrations of the C-H groups.

Figure 2D shows the FTIR spectra of pure TGB and TGB-fTiO, The first spectrum corresponds to TGB. The band observed at $3420 \mathrm{~cm}^{-1}$ is assigned to the acid group $=\mathrm{COOH}$. Characteristic bands of TGB are observed at 2934, 2729 and 2660 (aromatic $\mathrm{CH}$ stretching vibration), $1737 \mathrm{~cm}^{-1}$ (-C=C- ring stretching). The band at $1457 \mathrm{~cm}^{-1}$ corresponds to stretching vibrations of the C-H groups. Finally, bands at 1380, 1295 and $1273 \mathrm{~cm}^{-1}$ correspond to peaks for $\mathrm{C}-\mathrm{N}$ bending vibration.

The FTIR spectrum in Figure 3A corresponds to pure PHE and PHE-fTiO ${ }_{2}$. A great variety of bands were registered for the pure PHE infrared spectrum corresponding to different modes of vibrations of the various functional groups. At high energy, between 3700-2800 $\mathrm{cm}^{-1}$, the vibration bands related to the amino groups are observed at $3622 \mathrm{~cm}^{-1}$ for the C-NH-C of the group (CO) ${ }_{2} \mathrm{NH}$, at $3308 \mathrm{~cm}^{-1}$ to the stretching vibration of N-H groups followed by the two small shoulders at $3062 \mathrm{~cm}^{-1}$ which are characteristic of the stretching vibrations of the carbonyl groups. A doublet at 1690 and $1597 \mathrm{~cm}^{-1}$ can be observed which corresponds to the stretching vibrations of $\mathrm{C}=\mathrm{O}$ groups. The bands at 1494 and $1448 \mathrm{~cm}^{-1}$ are attributed to $\mathrm{CH}$ bending vibrations in the aromatic ring and the asymmetric $\mathrm{CH}$ stretching vibration in the aromatic ring takes place at 1385 and $1291 \mathrm{~cm}^{-1}$.

The FTIR spectrum of CBZ and $\mathrm{CBZ}-\mathrm{fTiO}_{2}$ are reported in Figure 3B. Characteristic bands of CBZ are observed at 3470 and $3159 \mathrm{~cm}^{-1}$ (-NH stretching of $\mathrm{NH}_{2}$ group), $3020 \mathrm{~cm}^{-1}$ (aromatic $\mathrm{CH}$ stretching vibration), $1679 \mathrm{~cm}^{-1}$ (-CO-R stretching vibration), 1603, 1488 and 1594 $\mathrm{cm}^{-1}(-\mathrm{C}=\mathrm{C}$ - ring stretching, $-\mathrm{C}=\mathrm{O}$ vibrations and $-\mathrm{NH}$ deformation) and $1383 \mathrm{~cm}^{-1}$.
The Figure $3 \mathrm{C}$ shows the FTIR spectra of pure LMT and LMT$\mathrm{fTiO}_{2}$. For pure LMT, the spectrum showed principal absorption peaks at $3453 \mathrm{~cm}^{-1}$ (N-H aromatic), $3213 \mathrm{~cm}^{-1}$ (C-H aromatic); 1644, 1619, 1583 and $1556 \mathrm{~cm}^{-1}\left(\mathrm{C}=\mathrm{N}\right.$ ); $1489-1405 \mathrm{~cm}^{-1}$ (four peaks in pairs for aromatic $\mathrm{C}=\mathrm{C}$ stretch benzene ring); 1321 and $1292 \mathrm{~cm}^{-1}$ (two weak intensity sharp peaks for $\mathrm{C}-\mathrm{N}$ bending vibration) and $1053 \mathrm{~cm}^{-1}$ (Ti-O).

Although the pattern AEDs-fTiO spectrums are similar to $\mathrm{fTiO}_{2}$ reference (Figure $2 \mathrm{~B}$ ), this could result from the low amount of AED used in the synthesis of these reservoirs $(100 \mathrm{mg}$ ) and the reason why signals from pure AEDs were masked by the characteristic intense signals of functionalized-titania reference.

The SEM micrographs of nanoparticles containing the drugs (AEDs- $\mathrm{fTiO}_{2}$, Figure 4) show a heterogeneous microstructure formed by irregular aggregates, which are spherical in shape and are approximately $0.30-0.48 \mu \mathrm{m}$ in diameter. The $\mathrm{fTiO}_{2}$ reference unchanged its structure. The results have good agreement with the $\mathrm{N}_{2}$ adsorption-desorption studies and suggest that the drug encapsulation does not has any effect on the $\mathrm{fTiO}_{2}$ structure.

The Figure 5 shows the resulting SEM images of a $\mathrm{fTiO}_{2}(\mathrm{a}, \mathrm{b})$ and CBZ- $\mathrm{fTiO}_{2}(\mathrm{c}, \mathrm{d})$ nanoparticles. In this case, samples were dispersed in ethanol following sonication for $10 \mathrm{~min}$ prior to analysis. With this treatment the samples can be observed more clearly at higher magnification where the structure of the aggregates of nanoparticles of $\mathrm{fTiO}_{2}$ (Figure 5b) and $\mathrm{CBZ}-\mathrm{fTiO}_{2}$ (Figure $5 \mathrm{~d}$ ) are approximately in the $300-400 \mathrm{~nm}$ range.

There were also obtained Energy Dispersive Spectroscopy (EDS) spectra from the zone where the micrographs were taken. The EDS spectra of the $\mathrm{fTiO}_{2}$ and $\mathrm{AED}-\mathrm{TiO}_{2}$ particles (Figure 6a-d) showed titanium and oxygen mainly, with no overlapping peaks. This implies that, following synthesis at room temperature, the nanostructured support material is free of contaminants and unreacted precursors.

In Figure $7 \mathrm{a}$ and $7 \mathrm{~b}$ show the $\mathrm{TiO}_{2}$ reference in amorphous formation with a particle size of $12-30 \mathrm{~nm}$. The antiepileptic material embedded in the particles is a polar substance acting as a directrix arranging them in a way they reduce the particle size as can be seen in Figure $7 \mathrm{c}$ and $7 \mathrm{~d}$ for carbamazepine with an particle size of 3-6 nm; "e", "f" for valproic acid with a sizes in the range of 4-6 nm and in Figure $8 \mathrm{a}$ and $8 \mathrm{~b}$ with tiagabine embedded in $\mathrm{TiO}_{2}$ with particle size of 7-20 nm; and phenytoin in "c" and " $\mathrm{d}$ " with particles of 7-12 nm. As the reference $\mathrm{TiO}_{2}$ matrix, the matrixes embedded with the drugs show amorphous formations showing that the formation of the particles is unaffected by the process of co-gelation as for crystalline structure of the $\mathrm{TiO}_{2}$, but it does reduce considerably the size of the particles.

In the Figure 9, thermographs of $\mathrm{fTiO}_{2}$ and $\mathrm{AEDs}-\mathrm{fTiO}_{2}$ are displayed after being thermally treated and correspond to the loss of organic components that is reflected with the weight loss observed in the TGA curve. The graph corresponding to $\mathrm{fTiO}_{2}$ shows several weights loss. The first one occurred at $70^{\circ} \mathrm{C}$ due to the removal of water adsorbed on titania's surface and residual solvent used during the synthesis. The second weight loss at $140^{\circ} \mathrm{C}$ corresponding to dehydration of the sample. One more was observed at $270^{\circ} \mathrm{C}$ induced by the gradual removal of the residual organic material from the alkoxide used during the $\mathrm{fTiO}_{2}$ preparation.

Also, the gradual weight loss at the region between 270 and $450^{\circ} \mathrm{C}$ is attributed to surface dehydroxylation. The percentages of weight loss observed to $\mathrm{fiiO}_{2}$ in each temperature are given in Table 2. The thermal-profile of $\mathrm{AEDs}-\mathrm{fTiO}_{2}$ has similar weight loss although in different percentage than the $\mathrm{fTiO}_{2}$ reference (Table 2). In these cases, around of $220-260^{\circ} \mathrm{C}$ the drug decomposition starts. This change is 


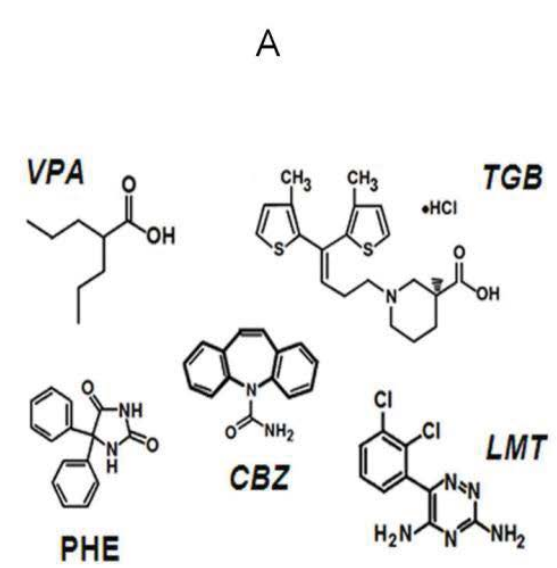

C

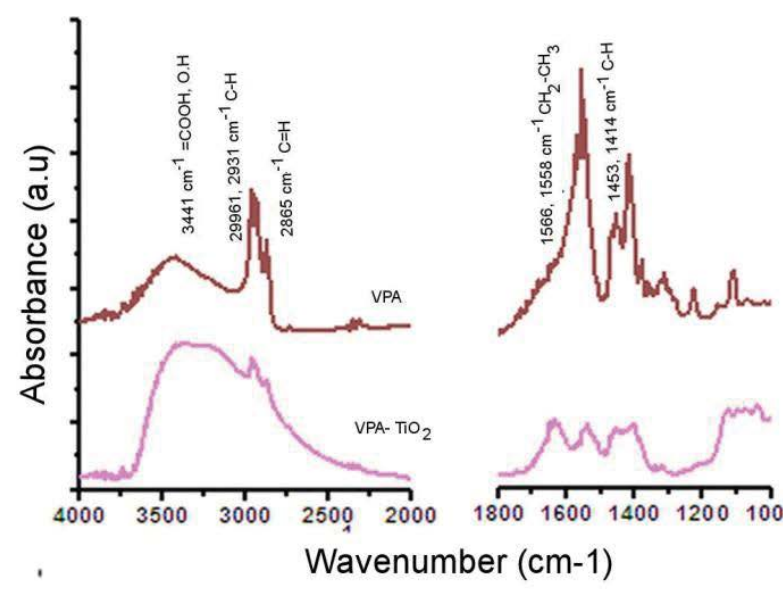

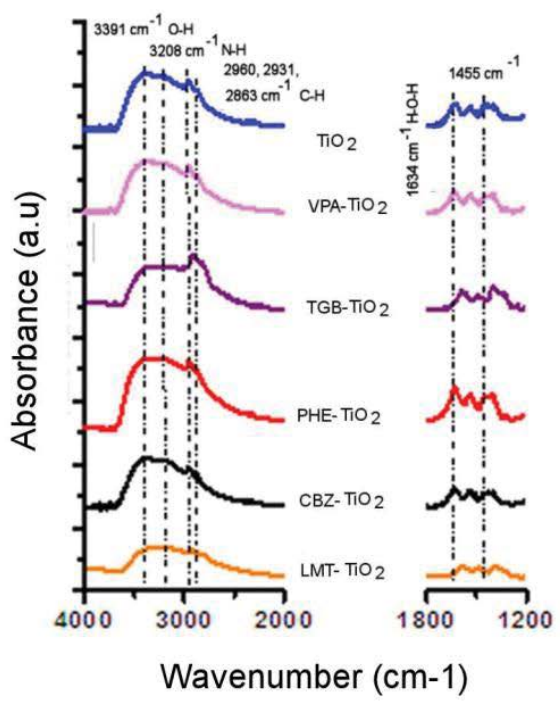

B

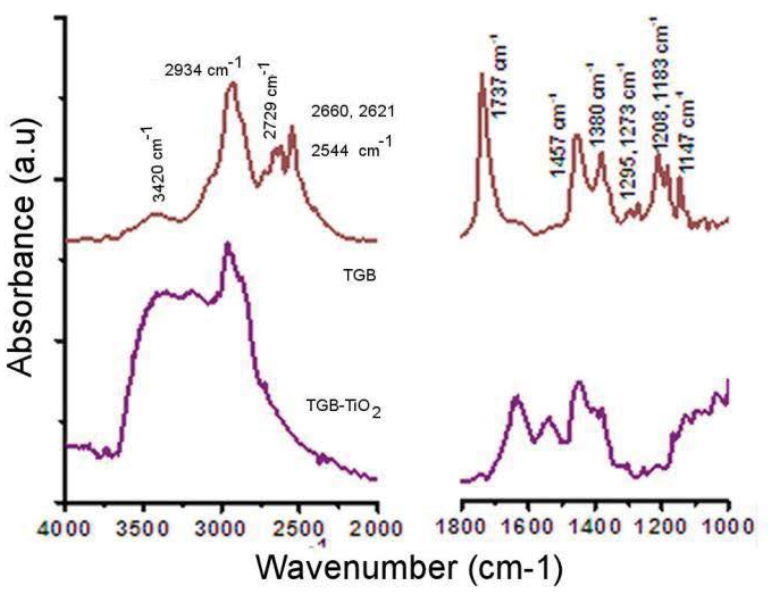

Figure 2: Chemical structures of AEDs employed (a) and infrared spectrums of functionalized-titania reference (fTiO $)_{2}$ and $A E D s-f T i O_{2}(b)$ samples. Infrared spectrums of VPA/VPA-fTiO 2 (c) and TGB/TGB- $-\mathrm{TTO}_{2}$ (d) samples, at two different intervals of wavenumbers at the medium infrared region: 4000 to $2000 \mathrm{~cm}{ }^{-1}$ and 1800 to 1000 $\mathrm{cm}^{-1}$.

due by removal of organic matter from the drug, drug vehicle and organic precursors used on the synthesis. The further weight loss at the temperatures above $400^{\circ} \mathrm{C}$ is due to the total dehydroxylation.

Taking in account these results, we can affirm that AEDs conserve their chemical nature when they are encapsulated into $\mathrm{fTiO}_{2}$ because their decomposition starts only at high temperatures. The $\mathrm{fTiO}_{2}$ matrix provides stability to the AEDs through weak hydrogen and/or electrostatic bonding and/or Van der Waals forces between them.

The rate of release of each AED was determined by measuring the concentration of the drug in the ACSF using UV-vis spectroscopy. Figure 10 displays the AEDs release profiles from the $\mathrm{fTiO}_{2}$ nanoparticles. All of them are similar in shape and characterized by the two regimes: first, an initial increase in the rate of drug release, and then a constant and slow release. This initial rate of increase is undoubtedly due to the presence of weakly adsorbed AEDs. In the case of CBZ, the initial rate of release was considerably lower than others AEDs (PHE, LMT and TGB). CVZ is displaced due to the fact that it contains 3 aromatic rings and 1 amide group. This fact produces a stereochemical effect in the titanium reservoir. This forms $\mathrm{NH}$ and $\mathrm{OH}$ energy bonds with fuctionalized titania during the $1^{\text {st }} 160$ hours, having the rather low liberation. Lower than the rest due to stereochemical effects. The pore diameter, as can be seen in Table 1, is the same for all antiepileptic AEDs. The CVZ however produces larger stereochemical effect with chemical formulae that make induce more Van-der Walls ligands that reduce the exit process.

In order to determine the drug release mechanism of AED from the $\mathrm{fTiO}_{2}$ nanoparticles, the experimental data were fitted to Peppas' equation [18]. The Peppas' equation is $(M t / M)=k(t)^{\mathrm{n}}$ where $M t / M$ is the fraction of drug released at time $t ; n$ is the diffusion exponent, which explains the transport mechanism of the drug through the material; and $k$ is the kinetic constant incorporating structural and geometric characteristics of the delivery system. Regarding $n$ values, if $n \leq 0.45$, the release mechanism follows Fickian diffusion; if $0.45<n<0.89$, the release occurs by non-Fickian diffusion. The parameter of the fits $n$ and the linear correlation coefficient $\left(\mathrm{R}^{2}\right)$ are given in Table 3 .

The values of parameter $n$ vary between samples from 0.44 to 0.96. Samples also have low correlation coefficients $\left(R^{2}=0.84-0.95\right)$. 

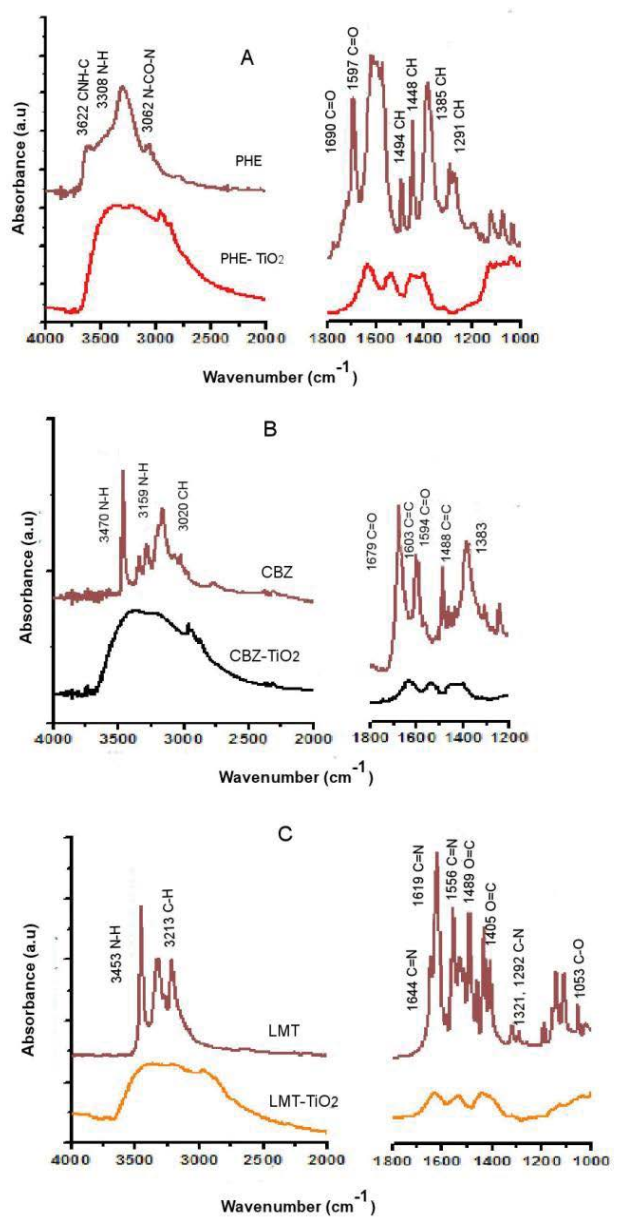

Figure 3: Infrared spectrum of PHE/PHE-fTiO 2 (a), CBZ/CBZ-fTiO ${ }_{2}$ (b) and LMT/LMT-fTiO 2 (c) samples, at two different intervals of wavenumbers at the medium infrared region: 4000 to $2000 \mathrm{~cm}^{-1}$ and 1800 to $1000 \mathrm{~cm}^{-1}$

All these data suggests that the release process is controlled by nonFickian diffusion. It is known that titania material has pores that are quite heterogeneous in length and surface roughness which may be the reason for more complex transport behavior [15]. Also, the drug dissolution greatly affects the drug release, thus, low solubility of the AEDs, like CBZ and LMT mainly, during the synthesis may hinder diffusion and may be the limiting step for the macroscopic release [3,5].

\section{Discussion}

In this study, we demonstrated that the same $\mathrm{fTiO}_{2}$ nanoparticles can encapsulate different active compounds (AEDs), provide chemical stability and promotes the controlled release of the drug. The sol-gel process was used to prepare $\mathrm{fTiO}_{2}$ nanoparticles containing AEDs and at the same time, this process served us to disperse the AED on the titania's matrix. The sol-gel method offers new possibilities for incorporating active agents within $\mathrm{fTiO}_{2}$ at mild conditions and for controlling their release kinetics from the gel matrix [19]. The $\mathrm{fTiO}_{2}$ obtained in this way have a high surface area and porosity allowing accommodate rather large amounts of the AED. In addition, the incorporation of AED, during the synthesis, allows encapsulation of larger amounts of the drug and its release during a longer period. Besides, this method is inexpensive, versatile and simple that provides easily reproducible gel properties [15].


Figure 4: Scanning electron micrographs of $\mathrm{fTiO}_{2}$ reference (a), VPA$\mathrm{fTiO}_{2}$ (b), TGB-fTiO 2 (c), PHE-fTiO 2 (d), CBZ-fTiO 2 (e) and LMT-fTiO ${ }_{2}$ (f) samples.
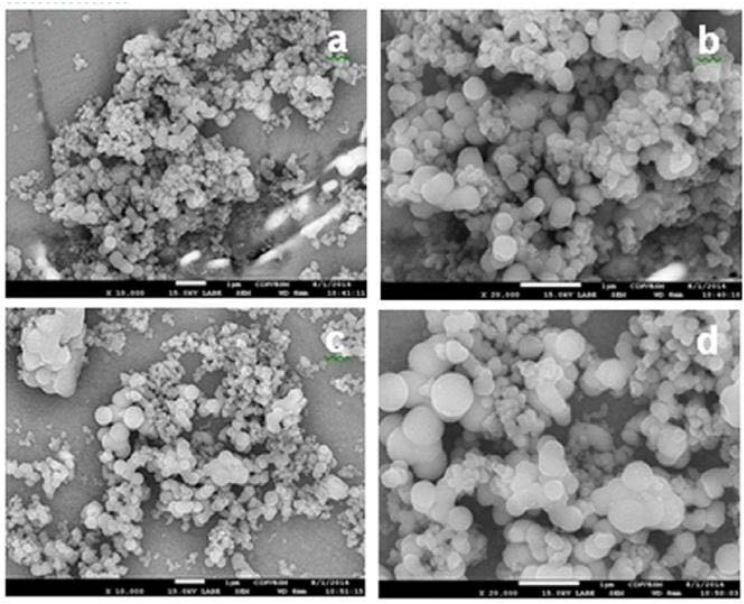

Figure 5: Scanning electron micrographs of $\mathrm{fTiO}_{2}$ reference $(a, b)$ and CBZ$\mathrm{fTiO}_{2}(\mathrm{c}, \mathrm{d})$ samples.

The $\mathrm{fTiO}_{2}$ nanoparticles can be designed to be used in crossing or penetrating $\mathrm{BBB}$, depending on their surface properties. In the present study, we have chemically modified the surface of titania with GABA, sulfate and phosphate ions in order to obtain a biocompatible titania. These functional groups can be anchored and generate positive and negative charges to the surface of the titania [20]. They can interact with the charges of the hydrophobic heads on the lipid bi-layer that conform the cell membrane and in certain way, titania is accepted as part of the cells. It was reported that $\mathrm{fTiO}_{2}$ had successfully acted as a carrier of copper complexes when they were released in different cancer cell lines [21,22]. 

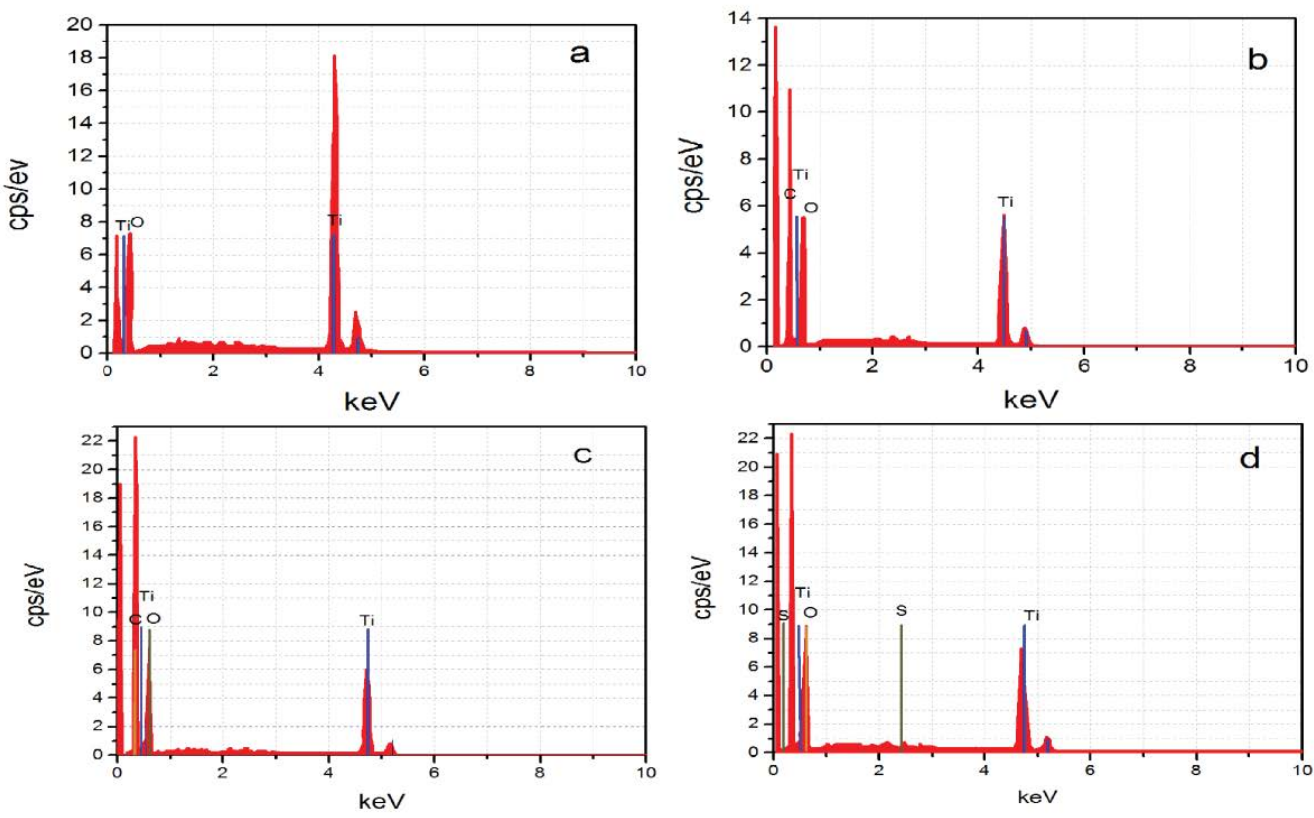

Figure 6: Energy dispersive spectroscopy (EDS) of: (a) fTiO reference, (b) CBZ-fTiO $_{2}$, (c) LMT-fTiO ${ }_{2}$, and (d) TGB-fTiO .

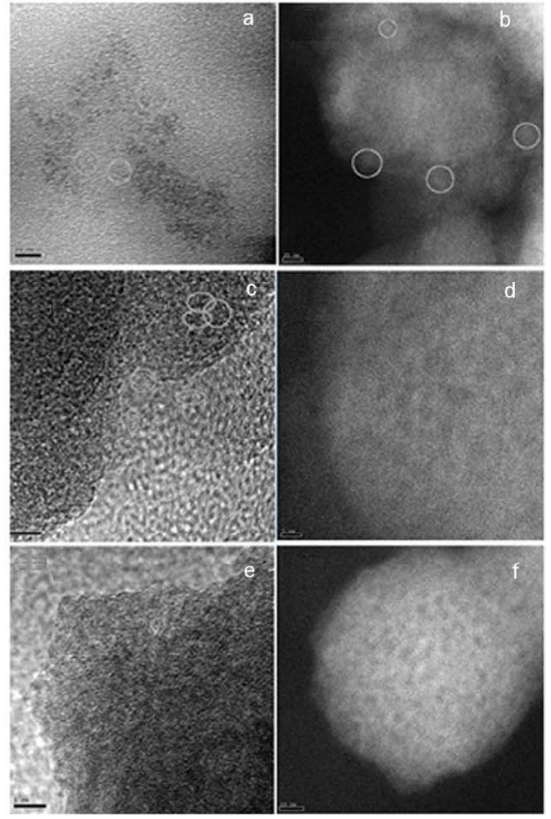

Figure 7: Trasmition Electron micrographs of $\mathrm{TTiO}_{2}$ reference (a), VPA-fTiO (b), TGB-fTiO ${ }_{2}$ (c), PHE-fTiO (d), CBZ--TTiO 2 (e) and LMT-fTiO ${ }_{2}$ (f) samples.

In addition, encapsulation of $\mathrm{AED}$ in $\mathrm{fTiO}_{2}$ can also prolong exposure of the drug by its controlled release. The morphology of $\mathrm{fTiO}_{2}$ consist of nanoparticles that conform aggregates which formed macroand mesopores [15] where the AED molecules were encapsulated and released from the nanoparticle. Some authors have investigated strategies to develop different kind of nanoscale delivery systems for some AEDs Nevertheless, these studies show rapid release patterns of the drug over the time (48 hours or less) generally [23-29]. Here, we demonstrated that $\mathrm{AEDs}-\mathrm{fTiO}_{2}$ release the AED in two steps: an initial

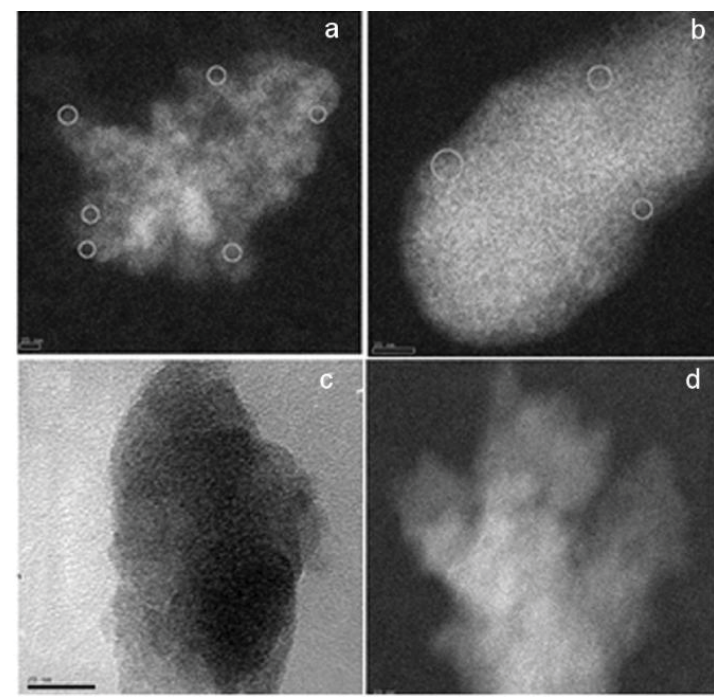

Figure 8: Transmition electron micrographs of $\mathrm{fTiO}_{2}$ reference $(a, b)$ and $\mathrm{CBZ}$ $\mathrm{fTiO}_{2}(\mathrm{c}, \mathrm{d})$ samples.

rapid release (useful for establishing the therapeutic dose of the drug) and subsequent slow sustained release (phase that help to maintain the dose of the drug for a prolonged time). These characteristics give them unique properties to these nanoparticles. On the other hand, the drugs used in this work for encapsulation are first line antiepileptic drugs commonly used to suppress the abnormal brain activity during a seizure acting by diverse mechanisms [1]. However, they are not well tolerated and present particular side effects like skin hypersensitivity, substantial teratogenicity and enzyme induction [1]. Also, some drugs like PHE, CBZ and LMT are poorly water soluble drugs and present irregular and delayed absorption attributed to slow dissolution rate [30]. Also, although approximately $70-80 \%$ of patients with new 


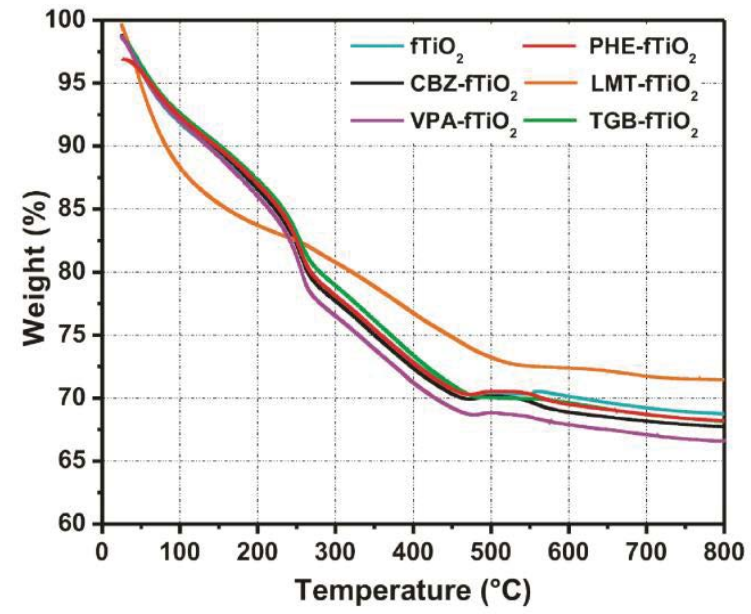

Figure 9: Thermogravimetric analysis curves for the tested samples $\left(\mathrm{fTiO}_{2}\right.$,

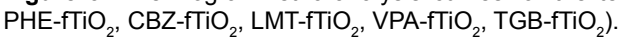

\begin{tabular}{|l|l|l|l|l|l|l|l|l|}
\hline \multicolumn{7}{|c|}{ Temperature $\left({ }^{\circ} \mathbf{C}\right)$} \\
\hline Samples & $\mathbf{6 0}$ & $\mathbf{7 0}$ & $\mathbf{1 4 0}$ & $\mathbf{2 2 0}$ & $\mathbf{2 5 0}$ & $\mathbf{2 7 0}$ & $\mathbf{4 7 0}$ & $\mathbf{5 2 0}$ \\
\hline $\mathrm{fTiO}_{2}$ & & 6 & 10 & 15 & 17 & 21 & 29.5 & \\
\hline $\mathrm{PHE}-\mathrm{TiO}_{2}$ & & 7 & 9.5 & 14 & 16 & 20 & 29.5 & \\
\hline${\mathrm{CBZ}-\mathrm{TiO}_{2}}$ & 6 & 10 & 15 & 17 & 21 & 30 & \\
\hline $\mathrm{LMT}_{2} \mathrm{TiO}_{2}$ & 7 & & 14 & & 17.5 & & & 27 \\
\hline VPA- $\mathrm{TiO}_{2}$ & & 6 & 10 & 15 & 18 & 21 & 31 & \\
\hline $\mathrm{TGB}_{2} \mathrm{TiO}_{2}$ & & 5.5 & 9 & 14 & 16 & 19.5 & 30 & \\
\hline
\end{tabular}

Table 2: Percentage of weight loss at different temperatures of fTiO2 reference and AEDs-TTiO2 samples.

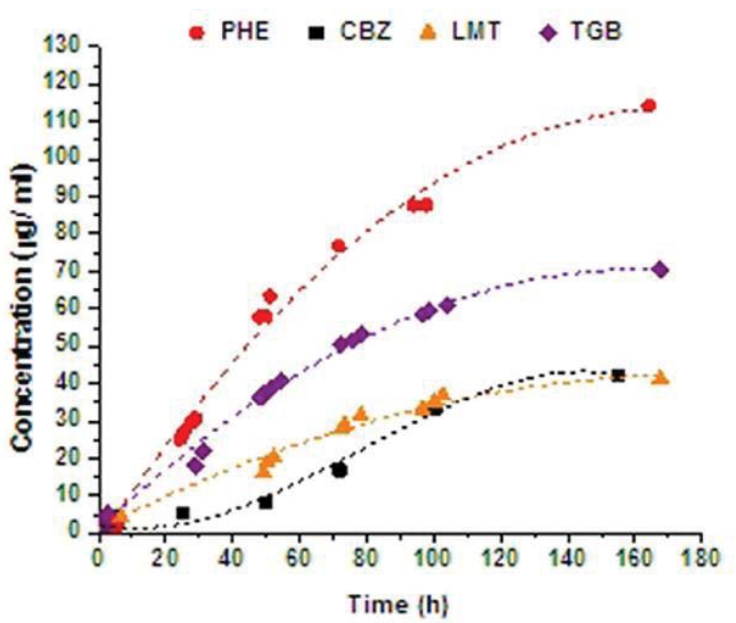

Figure 10: The in vitro release profiles of AEDs from $\mathrm{fTiO}_{2}$ carried out at room temperature in an artificial cerebrospinal fluid (PHE-red; TGB-green; CBZ-black; LMT-orange).

onset epilepsy eventually enter in remission with current AEDs, these medications fail to control seizures in $20-30 \%$ of patients, where a possible mechanism responsible for multidrug resistance is that the AED fails to reach its target in sufficient concentration because of overactive drug transporters in the BBB [31]. In base of the side effects, poor solubility and drug resistance related to AEDs, the strategy to encapsulate the AED in a nanoscale delivery system for controlled

\begin{tabular}{|c|c|c|}
\hline Samples & $\mathbf{n}$ & $\mathbf{R}^{\mathbf{2}}$ \\
\hline PHE-fTiO $^{2}$ & 0.96 & 0.9532 \\
\hline CBZ- $^{2} \mathrm{TiO}^{2}$ & 0.44 & 0.8367 \\
\hline LMT- $^{2}$ TiO $^{2}$ & 0.54 & 0.9855 \\
\hline TGB- TTiO $^{2}$ & 0.78 & 0.9641 \\
\hline
\end{tabular}

Table 3: Release kinetics data obtained from Peppas equation fits of AEDs-fTiO2 samples. $\mathrm{n}$ is the release exponent and R2 is the linear correlation coefficient.

release can be successful to improve its antiepileptic effect and to treat epilepsy. Therefore, the AEDs- $\mathrm{fTiO}_{2}$ nanoparticles are proposed to be promising drug delivery system for intranasal administration and promote the brain delivery of AEDs avoiding the administration of high doses of the drug to provide clinical effects. These $\mathrm{fTiO}_{2}$ nanoparticles can also provide protection for the drug from in vivo degradation.

Further studies are required to address the question of whether the intranasal administration of $\mathrm{AEDs}-\mathrm{fTiO}_{2}$ nanoparticles increase the AED brain concentrations in vivo and how is associated with an improved efficacy of the drug to prove the clinical efficacy of AEDs$\mathrm{fTiO}_{2}$. Also, it is necessary to investigate if these nanoparticles are able to improve the drug resistance in chronic epilepsy models.

\section{Conclusion}

The sol-gel method was suitable to functionalize titania nanoparticles and at the same time, it was useful to encapsulate antiepileptic drugs on the titania matrix. The $\mathrm{fTiO}_{2}$ nanoparticles provided chemical stability to AEDs encapsulated. Their morphology consisted to aggregates of nanoparticles. From $\mathrm{fTiO}_{2}$, different kinds of AEDs were released in controlled way, in two steps. These characteristics give them unique properties to these nanoparticles that might be useful to their intranasal administration and promote brain delivery of AEDs to control seizures. The meso-porous reservoirs has a high surface area, this fact allow increase the concentration of AEDs that can be anchored at the surface of the gel increasing liberation time. The use of a nano-device sol-gel with controlled release of drugs offer medical advantages such as the use of a decreased drug dose, which avoids neurological side effects and it represents a non-invasive route of administration.

\section{Acknowledgements}

We want to thank to CONACYT-Mexico for the financial support to carry out the present research. Also, we thank to INNN, UNAM, UAM-X and CINVESTAVMerida for their support.

\section{References}

1. Loscher W, Klitgaard H, Twyman RE, Schmidt D (2013) New avenues for anti-epileptic drug discovery and development. Nat Rev Drug Discov 12: 757-776.

2. Pathan SA, Jain GK, Akhter S, Vohora D, Ahmad FJ, et al. (2010) Insights into the novel three 'D's of epilepsy treatment: drugs, delivery systems and devices. Drug Discov Today 15: 717-732.

3. Lopez T, Manjarrez J, Rembao D, Vinogradova E, Moreno A, et al. (2006) An implantable sol-gel derived titania-silica carrier system for the controlled release of anticonvulsants. Materials Letters 60: 2903-2908.

4. López T, Ortiz E, Quintana P, González R (2007) A nanostructured titania bioceramic implantable device capable of drug delivery to the temporal lobe of the brain. Colloids and Surfaces A: Physicochemical and Engineering Aspects 300: 3-10.

5. López T, Quintana P, Ortiz-Islas E, E. Vinogradova, J. Manjarrez, et al (2007) Characterization of sodium phenytoin co-gelled with titania for a controlled drug-release system. Materials Characterization 58: 823-828.

6. López T, Alexander-Katz R, Castillo PM, González J, et al. (2009) Kinetic study of controlled release of VPA and DPH antiepileptic drugs using biocompatible nanostructured sol-gel TiO2. Journal of Materials Science 44: 5459-5468. 
Citation: López T, Cuevas JL, Jardón G, Gómez E, Ramírez P, et al. (2015) Preparation and Characterization of Antiepileptic Drugs Encapsulated in Sol-Gel Titania Nanoparticles as Controlled Release System. Med chem S2:003. doi: 10.4172/2161-0444.1000003

7. Lochhead JJ, Thorne RG (2012) Intranasal delivery of biologics to the central nervous system. Adv Drug Deliv Rev 64: 614-628.

8. Mistry A, Stolnik S, Illum L (2009) Nanoparticles for direct nose-to-brain delivery of drugs. Int J Pharm 379: 146-157.

9. Theresa MandElaine H (1996) Therapeutic opportunities for targeted liposomal drug delivery. Advanced Drug Delivery Reviews 21: 117-133.

10. Glen SandTeruo O (1996) Polymeric micelles as new drug carriers. Advanced Drug Delivery Reviews 21 107-116.

11. Lawrence MJ, Rees GD (2000) Microemulsion-based media as novel drug delivery systems. Adv Drug Deliv Rev 45: 89-121.

12. Panyam J, Labhasetwar $\vee(2003)$ Biodegradable nanoparticles for drug and gene delivery to cells and tissue. Adv Drug Deliv Rev 55: 329-347.

13. Bianco A, Kostarelos K, Prato M (2005) Applications of carbon nanotubes in drug delivery. Curr Opin Chem Biol 9: 674-679.

14. Parveen S, Misra R, Sahoo SK (2012) Nanoparticles: a boon to drug delivery, therapeutics, diagnostics and imaging. Nanomedicine 8: 147-166.

15. Lopez T, Kozina A, Ortiz-Islas E, Espinoza K, Gonzalez R (2011) In-situ Release of Antiepileptic Drugs from Nanostructured Reservoirs. INTECH Open Access Publisher.

16. Lopez T, Navarrete J, Conde R, Ascencio JA, Manjarrez J, et al. (2006) Molecular vibrational analysis and MAS-NMR spectroscopy study of epilepsy drugs encapsulated in TiO2-sol-gel reservoirs. J Biomed Mater Res A 78: 441-448.

17. Lopez T, Ortiz-Islas E, Vinogradova E, Manjarrez J, Azamar JA, et al. (2006) Structural, optical and vibrational properties of sol-gel titania valproic acid reservoirs. Optical Materials 29: 82-87.

18. Ritger, Philip L, Peppas, Nikolaos A (1987) A simple equation for description of solute release I. Fickian and non-fickian release from non-swellable devices in the form of slabs, spheres, cylinders or discs. Journal of Controlled Release 5: 23-36.

19. Chiriac AP, Neamtu I, Nita LE, Nistor MT (2010) Sol gel method performed for biomedical products implementation. Mini Rev Med Chem 10: 990-1013.

20. López T, Ortiz E, Alvarez M, Manjarrez J, Montes M, et al. (2010) Catalytic nanomedicine: Functionalisation of nanostructured cryptomelane. Materials Chemistry and Physics 120: 518-525.

21. Lopez T, Ortiz-Islas E, Guevara P, Gomez E (2013) Catalytic nanomedicine technology: copper complexes loaded on titania nanomaterials as cytotoxic agents of cancer cell. International Journal of Nanomedicine 8 581-592.

22. López T, Ortiz E, Guevara P, Gómez E, Novaro O (2014) Physicochemical characterization of functionalized-nanostructured-titania as a carrier of copper complexes for cancer treatment. Materials Chemistry and Physics 146: 37-49.

23. Jose S, Ansa CR, Cinu TA, Chacko AJ, Aleykutty NA, et al. (2013) Thermosensitive gels containing lorazepam microspheres for intranasal brain targeting. Int J Pharm 441: 516-526.

24. Samia O, Hanan R, Kamal el T (2012) Carbamazepine mucoadhesive nanoemulgel (MNEG) as brain targeting delivery system via the olfactory mucosa. Drug Deliv 19: 58-67.

25. Nair R, Kumar AC, Priya VK, Yadav CM, Raju PY (2012) Formulation and evaluation of chitosan solid lipid nanoparticles of carbamazepine. Lipids Health Dis 11: 72

26. Thomas MJ, Slipper I, Walunj A, Jain A, Favretto ME, et al. (2010) Inclusion of poorly soluble drugs in highly ordered mesoporous silica nanoparticles. Int J Pharm 387: 272-277.

27. Rajkumar M, Bhise S (2010) Carbamazepine-loaded porous microspheres for short-term sustained drug delivery. J Young Pharm 2: 7-14.

28. Kelmann R, Kuminek G, Teixeira H, Koester L (2007) Carbamazepine parenteral nanoemulsions prepared by spontaneous emulsification process. International Journal of Pharmaceutics 342: 231-239.

29. Gavini E, Hegge AB, Rassu G, Sanna V, Testa C, et al. (2006) Nasal administration of carbamazepine using chitosan microspheres: in vitro/in vivo studies. Int J Pharm 307: 9-15.

30. Rogawski MA, Loscher W (2004) The neurobiology of antiepileptic drugs. Nat Rev Neurosci 5: 553-564.

31. Brodie MJ, Barry SJ, Bamagous GA, Norrie JD, Kwan P (2012) Patterns of treatment response in newly diagnosed epilepsy. Neurology 78: 1548-1554.
This article was originally published in a special issue, Green Chemistry handled by Editor(s). Dr. Michael Shapiro, University of Maryland Baltimore USA 